periphery, there were focal areas of basaloid cells (figure-2). The pathological diagnosis was pilomatrixoma. No recurrence has been observed during 8 months' follow-up.

Conclusion Although pilomatrixoma occurs mostly in children, general pediatricians are not as well informed about this tumor as are dermatologists and otolaryngologists. We report this case for the benefit of pediatricians.

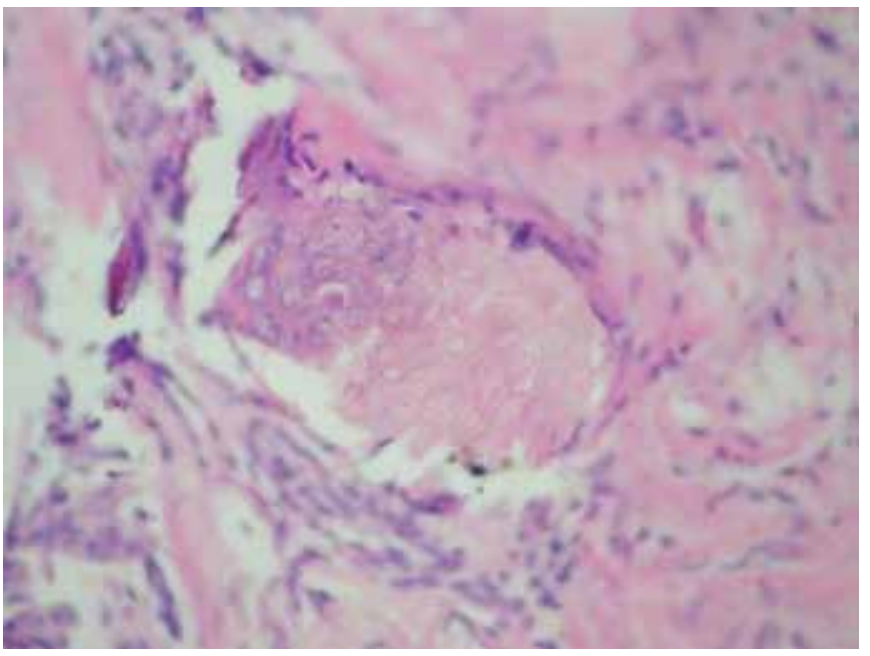

Abstract 626 Figure 1

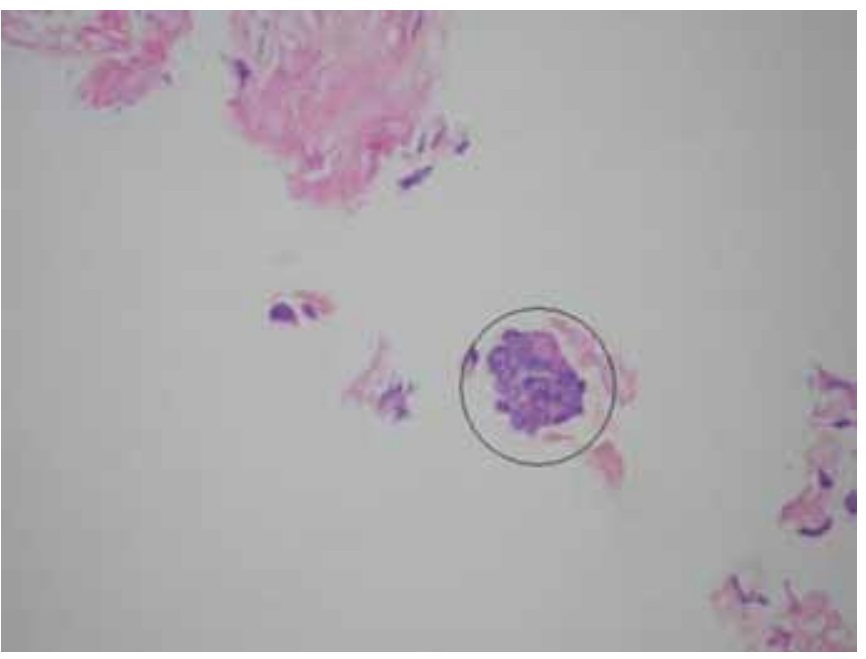

Abstract 626 Figure 2

\section{INITIAL EXPERIENCES WITH PROPRANOLOL TREATMENT OF INFANTILE HEMANGIOMAS: REPORT OF EIGHT CASES}

doi:10.1136/archdischild-2012-302724.0627

K Lajmi, A Hellara, S Hammami, S Haddad, C Ben Meriem, MN Gueddiche. Fattouma Bourguiba Hospital, Monastir, Tunisia

Background The infantile hemangioma (IH) is the most common benign vascular tumor in children. The most cases do not require therapeutic intervention. However, $10 \%$ of these cases require a treatment because of a life-threat, a functional trouble, a local complication or esthetic risk. We study the efficiency of Propranolol in the control of infantile hemangioma.

Methods Eight infants presented with 8 infantile hemangiomas treated by oral propranolol at a dose of $2 \mathrm{mg} / \mathrm{kg}$ body weight per day. Treatment outcomes were clinically evaluated.

Results The treatment was initiated during infancy in all cases (mean, 12.7 months). five patients were treated with $2 \mathrm{mg} / \mathrm{kg}$ per day, and three with $3 \mathrm{mg} / \mathrm{kg}$ per day Patients were monitored at initiation of treatment The first noticeable effects on propranolol treatment were the changes in color and softening of hemangiomas, followed by regression of their sizes and deep. Response to treatment was favorable; five showed total regression and in three cases a partial regression The average treatment duration in the remaining patients was 6.1 months. no adverse events were reported.

Conclusion Propranolol is an efficacious therapy for infantile hemangiomas. Risks and complications appear moderate. Prospective controlled trails are necessary to observe the effects on a long-term basis.

\section{CUTANEOUS SARCOIDOSIS ON A THREE YEARS OLD CHILD}

doi:10.1136/archdischild-2012-302724.0628

V Bexiga, M André, M Silva, A Afonso, AS Neto. Clinica Cuf Torres Vedras, Lisbon, Portugal

Background Sarcoidosis is a multisystemic granulomatous disorder characterized by the presence of noncaseating granulomas in tissues such as the skin, lung, lymph nodes, eyes, joints, brain, kidneys and heart. Sarcoidosis is a rare disease in paediatric age, with an incidence of $0.06 / 100.000$ habitants, in children younger than four years of age. Cutaneous involvement is more common in the pediatric population than in adults. Skin may be involved in $80 \%$ of affected children.

Case Report The AA present the case of a three years old girl, with unremarkable personal or familiar medical background, that presented a facial nonexsudative maculopapular lesion after insect bite. Four months later, in spite of various therapeutic approaches, the lesion was larger with erythematous-violaceous papules. She had no systemic symptoms.

The patient was referred to dermatology. Skin biopsy identified histopathologic features consistent with sarcoidosis. Pulmonar and ophthalmologic examination were normal. Serum angiotensin converting enzyme level was elevated.

She started oral prednisolone $1 \mathrm{mg} / \mathrm{kg} / \mathrm{d}$ with clinical improvement after one month.

Conclusion Dermatological manifestations of sarcoidosis should be considered in differential diagnosis of various chronic skin conditions such as eczema, acne or infections. The risk of development of systemic sarcoidosis in patients who present with the disease limited to the skin is unknown. However studies have shown that younger children have more risk of develop more serious sequelae.

\section{CALCINOSIS CUTIS OF LOWER EXTREMITIES}

doi:10.1136/archdischild-2012-302724.0629

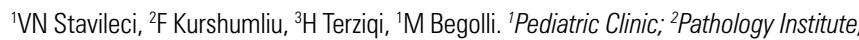
${ }^{3}$ Plastic Surgery, University Clinical Centre of Kosova, Prishtina, Albania

We present a 16 months old albanian female with firm nodules along her lower extremities, two months ago from now. No history of trauma or recent infections. Life history has no remarkable data, no medicaments has been used during pregnancy. Antirachitic prophylaxis just three months, $400 \mathrm{UI} /$ day. First steps, by age of 14 months. Family history unremarkable. No consanguinity. Physical examination: weight and stature on 50 centile. Hypertrichosis on the upper parts of the body and forehead. No other skin changes. All along the lower extremities are some hard, no sensitive nodules, different sizes and symmetrical spread all over the legs more expressed along crural region. Feels like cobbled when touched. Muscles are slight atrophic. Joints have normal range of motion with no walking difficulty. Other systems examination was unremarkable. Thyroid hormones, parathyroid hormone, Phosphor, Ca total and ionized, Total Proteins, Albumins, Lipidogram, Rheumatoid factors, ANA, CPK in the normal range. Other biochemical and microbiological parameters 
were normal. Abdominal ultrasound unremarkable. Heart ultrasound: unremarkable. Neurological examination, muscle strength and reflexes are normal. EMG: no miopathic changes. ENG: normal. Rtg of lower extremities found calcifications of soft tissues. Bones with no destruction or osteolises. Biopsy: on subcutan adipose tissue are found multiple and confluent foci of calcification called Calcinosis. She is without treatment to now and exacerbation of changes has been detected.

Conclusion Since there were no systemic metabolic disorders, tissue injury, or other founded reason, and the diagnose of Calcinosis cutis idiopathica was made.

Acknowledgements to nurses of nephrology department.

\begin{tabular}{l}
\hline 630 NEUROPSYCHOLOGICAL OUTCOME IN CONGENITAL \\
HYPOTHYROIDISM IN AN ITALIAN COHORT: THE \\
DEVELOPMENTAL OUESTIONNAIRE FOR CH (DOCH)
\end{tabular}

doi:10.1136/archdischild-2012-302724.0630

'S Bargagna, ${ }^{2} \mathrm{~A}$ Olivieri, ${ }^{2} \mathrm{C}$ Fazzini, ${ }^{1} \mathrm{M}$ Bozza. ${ }^{1}$ Stella Maris Scientific Institute, Pisa; ${ }^{2}$ stituto Superiore Sanità, Rome, Italy

Background and Aims Several studies on neuropsychological outcome in early treated children with congenital hypothyroidism $(\mathrm{CH})$. have demonstrated the presence of developmental disorders, in particular motor abilities language, emotions 1.2.3 The aim of this study was to to individuate the most vulnerable developmental domains and which risk factors are significantly associated with a poor outcome. To this end we have developed a developmental questionnaire on $\mathrm{CH}(\mathrm{DOCH})$.

Methods The DOCH has been created with dichotomous answers giving a score which hinders the dispersion of data and makes it easy to fill-in for a person knowing the child (clinical psychologist, physician, parents). It consists of 49 questions, in 7 domains - motor skills, personal autonomy, language development, social development, behaviour, biorhythms, and success in school. This questionnaire was designed for an easy way to collect data on developmental milestones and neuropsychological outcome in a large cohort of children with $\mathrm{CH}$ and their age-matched controls.

Results All domains of our questionnaire show major impairments in children with $\mathrm{CH}$ than in controls, in particular in personal autonomy for the group with thyroidal agenesis and social development for ectopic glands.

Conclusions We hypothesize that children with a more severe outcome are more frequently those of mothers affected by clinical and subclinical forms of hypothyroidism during pregnancy.

Refernces Oerbeck B, et al. Congenital Hypothyroidism: Influence of Disease Severity and L-Thyroxine Treatment on Intellectual, Motor, and School-Associated outcomes in Young Adults. Pediatrics 2003; 4:923-930.

Rovet JF. Congenital Hypothyroidism: long-term outcome. Thyroid 1999; Neuropsychological Developmental Congenital C Child Neuropsychological 2002.

\section{INFLUENCE OF ANTHROPOMETRICAL AND MENTAL STATUSES ON OCCURRENCE OF BEHAVIOUR DISEASES AMONG CHILDREN OF SCHOOL AGE}

doi:10.1136/archdischild-2012-302724.0631

K Lepiatsila. Belarussian State Medical University, Minsk, Belarus

To estimate influence of the anthropometrical status and personal features on occurrence of psychosomatic frustration, in particular, eating disorder, among children of school age.

We studied 57 children (age $15 \pm 1.3$ years). They were interviewed with Toronto Alexithimia Scale (TAS), scale of Rotter, standardized questionnaire "Aim-Means-Result" (AMR), scale of Rean and divided into 3 groups on the basis of body mass index (BMI). 1) $\mathrm{A}(\mathrm{BMI}<19$ $\left.\left.\mathrm{kg} / \mathrm{m}^{2}, 2\right) \mathrm{B}\left(19 \mathrm{~kg} / \mathrm{m} 2<\mathrm{BMI}<24 \mathrm{~kg} / \mathrm{m}^{2}\right), 3\right) \mathrm{C}\left(\mathrm{BMI}>24 \mathrm{~kg} / \mathrm{m}^{2}\right)$.

Results Based on the TAS $41 \%$ of boys showed higher than normal rates of alexithymia (A $-40 \%, \mathrm{~B}-60 \%, \mathrm{C}-100 \%$ ). Among girls (75\%,50\%,43\% respectively). AMR: $87 \%$ b and $82 \%$ g can't substantiate their goals. $50 \%$ of children had psychological barriers. Low-energy potential was recorded in Groups A and C (17\% and $25 \%$ ). $66 \%$ girls and $88 \%$ boys of all groups indicated optimal results. Scale of Rotter. Boys of Group C were dominated by external locus of control. Girls of such group were dominated by internal locus of control of life. Motivational pole is not strongly marked in $61 \%$ of girls.

The analysis of TAS showed an increasing trend of alexithymia among boys (from $59 \%$ to $100 \%$ ) and lower among girls (from $75 \%$ to $43 \%$ ) with an increase in BMI. Boys with a BMI> $24 \mathrm{~kg} / \mathrm{m}^{2}$ prevailed external locus of control, the girls - internal locus of control. In analyzing the results of the questionnaire of Rean boys tended to reduce the motivation to succeed and grow with the increase of negative motivation with increasing BMI (success from $70 \%$ to $25 \%$ ).

\section{EARLY INTERVENTION OF VISUAL IMPAIRMENT MAY PROTECT ADAPTIVE BEHAVIOUR IN DOWN SYNDROME?}

doi:10.1136/archdischild-2012-302724.0632

${ }^{1} \mathrm{~A}$ Dressler, ${ }^{2} \mathrm{M}$ Bozza, ${ }^{2} \mathrm{~V}$ Perelli, ${ }^{3} \mathrm{~S}$ Bargagna. 'Division of General Neuropediatrics and Neonatology, Medical University Vienna, Vienna, Austria; ${ }^{2}$ RCCS-Stella Maris Institute, ${ }^{3}$ Stella Maris Institute, Pisa, Italy

Down syndrome (DS) is one the most common genetic disorders. Little is known about the impact of visual disorders in DS on daily life. Our aim was to study the relation between the incidence of ocular manifestations and adaptive behaviour.

Methods We performed a detailed medical history, including ocular disorders. We tested Hirschberg's corneal reflex method, observed eye movements during fixation of a slowly moving object, cover test, and assessed the Vineland Adaptive BehaviourScales, as well as the Coloured Progressive Matrices. 52 DS individuals with an age range of 19 to 52 years. Results. We observed a high incidence of ocular anomalies (refractive errors in $59.2 \%$, strabism in $51 \%$, motility disorders in $63.3 \%$ and congenital bilateral cataract in $16.2 \%$ ), not differing with age. The occurence of visual disorders did neither lead to total lower adaptive level nor show an influence on cognition. Daily living skills were significantly lower in individuals with not corrected disorders, but these individuals showed a significant high co-morbidity of autism with childhood onset. We observed a majority of individuals with an adaptive functioning above the average. Hyperopia and the presence of refractive errors were significantly more frequent in individuals with an adaptive level above the average. Conclusions. Visual disorders lead to a poorer performance in adaptive behaviour in individuals with DS and also autism. This suggests that early intervention on refractive errors and visuomotor skills helps in the acquisition of daily living activities, which remain stable over the life-span. Therapeutic options for cataract need to be addressed early.

\section{WHAT IS THE EFFECTIVENESS OF DIMETHYLGLYCINE IN TREATING AUTISTIC SYMPTOMS IN CHILDREN: A SYSTEMATIC REVIEW}

doi:10.1136/archdischild-2012-302724.0633

M Haroon, G Ryan, M Randell, J Wilson, T Khatau, CHARGE: Child Health Applied Research Group, East-midlands. Leicester Partnership Trust, Leicester, UK

Background and Aims Dimethylglycine, an amino-acid derivative, has been proposed as a treatment for Autism. A systematic review was conducted to synthesize the best evidence relating to this topic. 